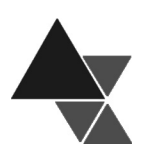

\title{
Direito Humano à Alimentação: marco conceitual e legal para a presença do setor público brasileiro no abastecimento de Frutas, Legumes e Verduras ${ }^{1}$
}

\author{
Rubia Cristina Wegner ${ }^{2}$
}

O objetivo deste trabalho é apresentar as Centrais de Abastecimento (CEASAs) como estruturas que apresentam condições para centralizarem ações reguladoras do abastecimento de Frutas, Legumes e Verduras. O Direito Humano à Alimentação (DHA) representaria embasamento para a regulação pública em aspectos como padronização e classificação desses alimentos e das suas embalagens. Parte-se da compreensão do abastecimento como um dos determinantes das condições de acesso e de disponibilidade de alimentos nas cidades. A vigência de um Sistema Nacional de Centrais de Abastecimento (SINAC) de 1972 a 1986 serviu de parâmetro na análise da configuração entre setor privado - representado pelos supermercados - e setor público - centrais públicas de abastecimento - na distribuição e comercialização de frutas, legumes e verduras. O trabalho se organizou por meio de uma seção que trata o DHA em termos conceituais e como fundamento para presença do setor público no abastecimento e de outra seção na qual se destaca os limites para a realização progressiva desse direito no âmbito de falhas da presença do setor público no abastecimento via CEASAs. Entre ambas é apresentada a metodologia utilizada, quais sejam, entrevista semi-estruturada, revisão bibliográfica, tabulação dos dados da Pesquisa de Orçamentos Familiares (POF-IBGE) 2002-2003 e 2008-2009, e da plataforma de dados para as centrais de abastecimento (BI-PROHORT). Dentre as principais conclusões se destaca a necessidade de se aproveitar as CEASAs na regulação pública do abastecimento, fundamentando-se, assim, a realização do direito ao alimento.

Palavras-chave: Direito Humano à Alimentação, abastecimento alimentar, distribuição de Frutas, Legumes e Verduras.

\section{Human right to food: conceptual and legal framework for the presence of the public sector in the Brazilian fruits and vegetables supply}

The aim of this paper is to present the Central Public Supply (CEASAs) as structures which are conditions to centralize regulatory actions in the supply of fruits and vegetables. The Human Right to Food would be the basis for official regulations in areas such as the standardization and classification of foods and their packaging. It starts by understanding that supply is a determinant of the conditions for access and availability of food in a city. The term of a National System of Wholesale Markets (SINAC) from 1972 to 1986 served as a parameter in the configuration between the private sector - represented by supermarkets - and the public sector - central government supply distribution and marketing of fruits and vegetables. The work was organized by a section dealing with the Human Right to Food in conceptual terms and as a foundation for public sector presence in the supply and another section which stresses the limits to the progressive realization of this right under the presence of failures in the public sector, via the CEASA suppliers. Between them, the methodology used, namely, semi-structured interviews, literature review, data tabulation of the Household Budget Survey (POF-IBGE) 2002-2003 and 2008-2009, and the data platform to the central supply (BI-PROHORT) is shown. Key findings include the need to seize the CEASAs as a public tool for the regulation of supply, thereby setting the basis to achieve the right to food.

Key-words: Human Right to Food, food supply, distribution of fruits and vegetables.

\footnotetext{
${ }^{1}$ Esse artigo deriva do projeto "O novo paradigma na distribuição de alimentos e o papel do setor público: enfoque no direito humano à alimentação" desenvolvido durante o ano de 2009, financiado pela Organização das Nações Unidas para Agricultura e Alimentação (FAO/ONU) e sob orientação do Prof. Dr. Walter Belik.

2 Mestre pelo programa de Desenvolvimento Econômico do Instituto de Economia da Universidade Estadual de Campinas (Unicamp). Ex-bolsista CNPq. Correspondência: Rua do Sol, 148, Sobrado 65. Barão Geraldo. CEP 13085-260. Campinas, SP. Fone: 55 (19) 3287-7709. E-mail: rubiawegner@hotmail.com.
} 


\section{INTRODUÇÃO}

Centrais de Abastecimento (CEASAs) são empresas estatais ou de capital misto que apoiam a realização de trocas comerciais de hortigranjeiros de tal modo que devem promover, desenvolver, regular, dinamizar e organizar a comercialização desses produtos; em outras palavras, CEASA é uma personalidade jurídica que administra um ou mais entrepostos atacadistas. A implantação dessas estruturas nas principais cidades de países da América Latina se baseou em sistemas de abastecimento de países como França e Espanha sob orientação da Organização das Nações Unidas para Agricultura e Alimentação (FAO/ONU), sobretudo nos anos 1970. No Brasil, vinte e uma CEASAs foram construídas entre 1972 e meados da década de 1980. Elas estavam articuladas entre si, constituindo o Sistema Nacional de Abastecimento (SINAC), que era um modelo político e organizacional pautado por uma lógica sistêmica para regulamentar a comercialização de hortigranjeiros [1]. O SINAC, estabelecido em 1972, constituía também um programa de investimento em infraestrutura cuja execução coube ao Grupo Executivo de Modernização do Abastecimento (GEMAB) e funções de coordenação, controle técnico, administrativo e financeiro couberam à Companhia Brasileira de Alimentos (COBAL).

Esse Sistema de Centrais de Abastecimento (SINAC) foi criado sob a égide do "Estado desenvolvimentista" com diretrizes estabelecidas pelo I Plano Nacional de Desenvolvimento. Nesse período, o país adentrava nos processos de urbanização e industrialização, determinando a formação de mercado interno para alimentos, bem como pressão da demanda urbana por hortigranjeiros. Dado esse contexto, a preocupação do governo federal consistia em abrandar o custo de vida especialmente o custo de reprodução da força de trabalho via poder de compra dos salários [2]. $\mathrm{O}$ investimento público em infraestrutura para as CEASAs indicava que o abastecimento era entendido pelo setor público como um serviço importante para o funcionamento das demais atividades econômicas.

O SINAC também deveria contribuir para aprofundar o varejo de produtos hortifruti, principalmente por meio de supermercados [1]. Ao longo das décadas de 1960/70, teria ocorrido a modernização do varejo desses alimentos sob um processo marcado pela concentração em estratégias de diferenciação do produto, coexistindo com pequenos varejistas independentes [3]. Nos anos 1980, os supermercados começavam a orientar a comercialização de Frutas, Legumes e Verduras 3 (FLV) por meio do estabelecimento de contratos com produtores. Aspecto este que contribuiria para reduzir o peso dos entrepostos atacadistas - espaços físicos onde produtores e atacadistas se reúnem para intercâmbio de hortigranjeiros - na comercialização desses produtos: as transformações na esfera da circulação caracterizaram-se, portanto, pela tendência à concentração de capital, com a consolidação do grande capital comercial ${ }^{[4]}$.

A crise fiscal enfrentada pelo Estado brasileiro $^{4}$ contribuiu para que, em 1986, se interrompesse o aprofundamento do modelo SINAC. A COBAL foi autorizada a transferir o controle acionário das vinte e uma CEASAs existentes para os respectivos Estados e municípios [1], o que efetivamente ocorreu em 1988. Desse modo, pulverizou-se a organização do abastecimento em termos de política pública. Numa perspectiva ampliada, a própria concepção sobre o tamanho do Estado na economia brasileira se transformou. Passou-se a defender que esse tamanho deveria ser o mínimo possível, logo, os investimentos públicos em infraestrutura se esvaneceram [5]. E o programa de privatização, nas trilhas do neoliberalismo, impulsionou $\mathrm{O}$ reordenamento da presença do Estado na economia, ou seja, de empreendedor ele deveria passar a regulador/fiscalizador ${ }^{6}$. A A Companhia de Entrepostos e Armazéns Gerais de São Paulo (CEAGESP, São Paulo, SP), por exemplo, foi inclú́da ${ }^{5}$ no Plano Nacional de Desestatização, em 1998, para saldar dívida do Estado de São Paulo com a União.

Para sustentar a abertura da economia brasileira $^{6}$, tornou-se imprescindível captar Investimento Externo Direto (IED). Assim, a entrada de redes estrangeiras de supermercados esteve facilitada. E com isso, elas incorporaram à distribuição e comercialização de FLV, logística e novas tecnologias

\footnotetext{
${ }^{3}$ Nesse trabalho, para se referir a esses alimentos utilizou-se termos como: FLV, hortifruti, frutas e legumes (dados Pesquisa de Orçamentos Familiares (POF), Instituto Brasileiro de Geografia e Estatística (IBGE) e frutas e hortaliças (dados Programa de Modernização do Mercado Hortigranjeiro - PROHORT). Não foi objetivo empreender uma análise epistemológica e semântica desses termos.

${ }^{4}$ Para uma leitura mais aprofundada, recomenda-se: Davidoff C, Paulo RC. Dívida externa e política econômica: a experiência brasileira nos anos setenta. São Paulo: Brasiliense, 1984.

${ }^{5}$ A CEASA Minas (MG) está sob o mesmo processo.

${ }^{6}$ Recomenda-se a leitura do trabalho: Notas sobre a natureza do processo de globalização de Luciano Coutinho. Economia e Sociedade. 1995;4:21-6.
} 
de informação [7], além de paulatinamente conquistarem espaço em relação a outros equipamentos varejistas, como feiras livres, por exemplo. Coadunada à estratégia da abertura da economia, a estabilidade de preços alcançada com o Plano Real, a partir de 1994, teria retirado do poder público a necessidade de intervir nos preços dos alimentos (de modo geral) como fizera em anos de elevada inflação ${ }^{[8]}$.

Nessa perspectiva, o varejo de alimentos experimenta um processo de reestruturação e de consolidação expressivo marcado pela entrada de novas redes supermercadistas com atuação internacional [7]. Com base nos dados do Ranking da Associação Brasileira de Supermercados (ABRAS), em 1996, existiam 43,7 mil lojas de supermercados no país com faturamento anual de R\$ 46,8 bilhões; em 2009, eram 55,57 mil lojas com faturamento anual de $\mathrm{R} \$ 121,18$ bilhões, em valores correntes. As cinco maiores redes do setor 7 , em 2009 corresponderam a 63\% do faturamento total e são de capital predominantemente estrangeiro.

Ao mesmo tempo em que as CEASAs se depararam com uma série de problemas técnicos e gerenciais, principalmente pela desarticulação do SINAC, uma vez que "deixou de haver um 'pensar grande' para o sistema, próprio de uma ação articuladora federal" [9]. Por outro lado, elas seguem sendo empresas públicas das quais Estados e municípios são acionistas majoritários. As CEASAs seguem também exercendo sua função primordial: reunir agentes da comercialização não apenas de FLV e demais componentes do setor hortigranjeiro ${ }^{8}$, mas também de pescados, entre outros produtos frescos. $\mathrm{O}$ setor FLV carece de uma organização aprofundada e abrangente, tendo em vista seus aspectos interrelacionados referentes à produção, classificação e rotulagem, padronização de embalagens [10], que por constituírem padrões para negociações comerciais entre os entes dessa cadeia, impactam o acesso físico e monetário pela população urbana. $\mathrm{O}$ alto valor nutricional desses alimentos [11] e, assim, sua direta

\footnotetext{
${ }^{7}$ Carrefour Com. Ind. Ltda.; Companhia Brasileira de Distribuição; WalMart Brasil Ltda.; GBarbosa Comercial Ltda. (Sede em Sergipe) e Irmãos Bretas Filhos e Cia Ltda. (Sede em Minas Gerais). Com base em informações do Ranking da Associação Brasileira de Supermercados (ABRAS) divulgado, em 2010, na Revista Super Hiper.

8 Seriam eles: ovos, aves, flores, orgânicos, hidropônicos e processados. Com base no Sistema de Consultas Gerenciais do Programa de Modernização do Mercado Hortigranjeiro (BIPROHORT).
}

ligação com a Segurança Alimentar e Nutricional (SAN) é mais um fator para se defender da regulação pública do seu abastecimento nas áreas urbanas.

Na década de 1990, o acesso da população ao consumo de alimentos seguros, em bases permanentes e sem comprometimento da satisfação de outras necessidades básicas constituía o cerne da proposição feita pela sociedade civil ao governo. Defendia-se ${ }^{9}$ apropriação do conceito de segurança alimentar como elemento estratégico em políticas econômica e social de modo a induzir a mudanças no próprio padrão de desenvolvimento, uma vez que sob o neoliberalismo, políticas sociais passaram à margem nos gastos públicos [12]. Ademais, esse entendimento da SAN estava inserido em um debate mundial que culminou na consolidação do acesso ao alimento como questão de direito humano. $\mathrm{Na}$ década de 2000, o governo brasileiro acompanha e, em certa medida, influencia, as negociações internacionais sobre a realização do direito ao alimento [13]. Cumpre destacar que essa orientação sobre o acesso aos alimentos se combina com aquele tratamento focalizado da política social, iniciado em fins dos anos 1980 [14].

Em 2010, o Direito Humano à Alimentação (DHA) passou a compor os direitos sociais da Constituição brasileira por meio da aprovação da Proposta de Emenda Constitucional (PEC), número 47, cujos trâmites iniciaram em 2003. Anterior à aprovação dessa emenda, mas também com embasamento na garantia do DHA, foi a promulgação, em 2004, da Lei Orgânica de Segurança Alimentar (LOSAN). Ao prever a criação de um Sistema Nacional de Abastecimento Alimentar (SISAN) essa lei confere perspectiva de integração e intersetorialidade no tratamento da SAN [15]. Apesar da relação direta entre abastecimento e acesso aos alimentos, é imprescindível ressaltar que já não existe uma regulamentação nacional dessa atividade, apesar de todos esses compromissos assumidos pelo Estado brasileiro com a realização desse direito.

\footnotetext{
9 A criação do Conselho Nacional de Segurança Alimentar (CONSEA) - órgão vinculado à presidência da República - foi elemento importante dessa configuração da Segurança Alimentar e Nutricional (SAN) em políticas de Estado. Representou um espaço de debate entre governo e sociedade civil, priorizando programas sociais. Em meados da década de 1990 foi substituído pelo Conselho Consultivo da Comunidade Solidária, marcando também uma nova apropriação da segurança alimentar, qual seja, de meta estratégica de política econômica. No governo Lula, o CONSEA é restabelecido [13].
} 
Neste trabalho, o objetivo é apresentar as CEASAs como estruturas que possuem condições para centralizar ações reguladoras do abastecimento de FLV, tendo em vista o compromisso assumido pelo Estado brasileiro com o DHA. O trabalho se organizou por meio de uma seção que trata do DHA em sua dimensão conceitual, destacando-se o consumo diário de hortifruti e a existência de canais de comercialização eficientes - e capazes de induzir à equidade - como elementos primordiais para a realização desse direito. $\mathrm{Na}$ seção seguinte, discorre-se sobre os limites para a realização progressiva do DHA, no País, com base nos problemas enfrentados pelas CEASAs, bem como nas lacunas de políticas públicas para o estabelecimento de critérios para comercialização de frutas e hortaliças. Entre ambas, está a seção destinada a esclarecer a metodologia utilizada.

\section{METODOLOGIA}

Abastecimento alimentar é abrangente nos elos e entes que o tornam efetivo. Além de conter forte elemento geográfico, o que se sobressai em um país de extensão continental como é o Brasil. Produtos hortifruti são perecíveis e, no país, sua produção se dá de maneira sazonal e fragmentada por entre as regiões, haja vista suas diferentes condições edafoclimáticas. $\mathrm{O}$ processo de colheita é demorado e penoso. Não há, entre os produtores, o seguimento de iguais padrões de tecnologia de produção e também se observam diferentes práticas de manejo ${ }^{[16]}$.

Para esses alimentos frescos a sistematização nacional de dados sobre produção, comercialização, transporte, logística e consumo é incipiente, quase inexistente. Por outro lado, a dinâmica atual na distribuição e comercialização desses produtos é complexa: as inovações de logística e em Tecnologia de Informações (TIC) introduzidas pelos supermercados; as centrais de abastecimento não perderam sua importância nessa atividade - sobretudo em relação a regiões como Norte e Nordeste do país, porém enfrentam problemas de gestão e de logística que encobrem seu real papel no abastecimento; consumidores cada vez mais exigentes por qualidade e, também, por preços, o que seria próprio do atual regime alimentar [17]. Frente a esse contexto, o setor público brasileiro não utiliza meios e instrumentos bem estabelecidos para regular a atividade abastecedora.

Neste trabalho, buscou-se por entes - como supermercados, centrais de abastecimento, empresas atacadistas - com atuação nacional, cuja sede estivesse no Estado de São Paulo. Ainda que a amostra seja reduzida, sua significância - em termos de interligação com outras regiões do país e de estabelecimento de padrões para distribuir e comercializar hortifruti em âmbito nacional - permite extrair conclusões importantes para a regulação pública no abastecimento como um dos eixos da política de SAN, com as CEASAs assumindo função de agentes principais.

Escolheram-se como componentes da amostra para a entrevista semi-estruturada, as seguintes unidades de análise: centrais de abastecimento; redes de supermercado e empresas atacadistas.

As centrais de abastecimento: CEASA Campinas (SP), considerada modelo de central municipal, além de exercer funções essenciais na política de abastecimento e em programas federais de SAN e a CEAGESP (São Paulo, SP), que representa ponto de referência na atividade atacadista nacional, além de cumprir relevante papel no abastecimento de vários municípios brasileiros. É uma das principais centrais atacadistas da América Latina. Vale considerar que a CEASA Campinas comercializa volumes robustos de hortigranjeiros apesar de estar localizada no mesmo Estado que a maior central do país. $\mathrm{Na}$ CEAGESP foram entrevistados a técnica responsável pelo Centro de Qualidade em Horticultura (CQH) e um gestor, em 11 e 26 de janeiro de 2010. Na CEASA Campinas, também se entrevistou um dos seus gestores, em 31 de janeiro de 2010.

Além desses entes, incluíram-se as redes de supermercado: Companhia Brasileira de Distribuição (Grupo Pão de Açúcar); Grupo Carrefour, Oba Horti Fruti e Supermercados Covabra.

A Companhia Brasileira de Distribuição (CBD) é uma das cinco maiores redes de supermercado no Brasil e conta com um sistema logístico robusto, bem como com medidas inovadoras para a venda de hortifruti. Em 2009, o seu faturamento bruto foi de R \$ 26,22 bilhões $-21,5 \%$ do faturamento total - com 1.080 lojas num total de 1,7 milhões metros quadrados de área de vendas e 11,2 mil checkouts. Nela, dois gerentes para setor de FLV foram entrevistados: um gerente de compras do setor verduras e um gerente de compras do setor frutas. Em 05 de dezembro de 2009 e 08 de março de 2010, respectivamente. 
O Grupo Carrefour é também uma das cinco maiores redes de supermercado do país. Em 2009, o seu faturamento bruto foi de $R \$ 26,6$ bilhões $-22 \%$ do faturamento total - com 611 lojas que ocupam uma área total de vendas igual a 1,4 milhões de metros quadrados com 8,2 mil checkouts. Nessa rede, em 10 de abril de 2010, dois gerentes responsáveis pela área de vendas foram entrevistados.

Oba Horti Fruti iniciou suas atividades sob a forma de "sacolão" e se transformou em uma loja especializada no varejo de FLV ${ }^{10}$. É considerada modelo entre os gerentes comerciais de outras redes de supermercados, embora não adote $\mathrm{o}$ instrumento de logística das duas maiores redes, tais como: plataformas logísticas, contrato com os produtores. Entrevistaramse, nos boxes dessa empresa na CEASA Campinas, em dezembro de 2009 e janeiro de 2010, dois gerentes comerciais responsáveis por todo o processo de distribuição e comercialização desses produtos. Entrevistou-se também, em 16 de janeiro de 2010, o gerente de compras de hortifruti do supermercado Covabra, que possui duas lojas na cidade de Campinas (SP) e outras nove no Estado de São Paulo. Essa empresa ocupou, em 2009, a trigésima primeira posição no Ranking ABRAS; apresentou faturamento bruto de $\mathrm{R} \$ 361$ milhões - 0,3\% do faturamento total; 154 checkouts; 15 mil metros quadrados de área de vendas e 1,5 mil funcionários.

As redes WalMart Brasil Ltda. e Companhia Zaffari Comércio e Indústria se recusaram a colaborar com essa pesquisa, porque suas informações a respeito da sua organização em torno da venda de FLV seriam confidenciais. Além desses, não se contou com a colaboração da Secretaria de Abastecimento de São Paulo e da autarquia da Prefeitura Municipal de Campinas - Serviços Técnicos Gerais (SETEC) - para se obter informações sobre as feiras livres dessas cidades.

E para analisar a atuação dos atacadistas, escolheu-se Benassi, que é um dos maiores distribuidores desses alimentos no país, sendo, inclusive, responsável pelo suprimento desse produto nas lojas da bandeira Pão de Açúcar da Companhia Brasileira de Distribuição localizadas na cidade de São Paulo (SP). Assim, a rede supermercadista, com mais expressivo aparato logístico de distribuição desses alimentos, recorre a uma empresa atacadista, em

${ }^{10}$ Essa empresa não consta no Ranking ABRAS, por isso ela não foi caracterizada como as demais. detrimento de seus centros de distribuição, para abastecer suas lojas. Nota-se a complexidade envolvida nessa questão.

O roteiro utilizado nessas entrevistas foi estruturado de modo a se materializar nas seguintes classes de informações a respeito da: (a) atuação das centrais de abastecimento: alternativas para reformulação do mercado atacadista brasileiro; o papel que esses entrepostos poderiam e/ou deveriam exercer no abastecimento de hortifruti; dificuldades para as CEASAs instrumentalizarem as atividades de classificação e controle de qualidade de frutas e hortaliças; (b) supermercados: o papel que as grandes redes enxergam para as centrais de abastecimento, tendo em vista a opção dessas redes pelo uso de plataformas logísticas; importância do setor FLV em termos de faturamento e do aparato logístico que exigem; a importância que os entrepostos atacadistas mantêm; a forma como a SAN tem sido incorporada à estratégias concorrenciais pelo setor supermercadista; (c) atacadistas: basicamente as perguntas se articularam por dois eixos: se a distribuição moderna, com núcleo nas centrais de distribuição, é de fato eficiente e sobre o papel remanescente das centrais de abastecimento. Nesse último eixo, estaria o aspecto das possíveis necessidades das centrais em termos de política pública. Ao todo, foram realizadas oito entrevistas.

As fontes de dados utilizadas foram: o Sistema de Consultas Gerenciais formulado pelo Programa de Modernização do Mercado Hortigranjeiro (BIPROHORT) ${ }^{11}$ com informações sobre as centrais de abastecimento e a revista SuperHiper cuja publicação cabe à Associação Brasileira de Supermercados (ABRAS). $\mathrm{Na}$ Pesquisa de Orçamentos Familiares (POF) divulgada pelo Instituto Brasileiro de Geografia e Estatística (IBGE), correspondente aos biênios 2002/2003 e de 2008/2009, buscaram-se dados a respeito dos hábitos de consumo da população urbana. Nesse último biênio, a POF se valeu de uma amostra com 55.970 domicílios incluindo 56.091 famílias, das quais $84,42 \%$ residem na área urbana, o equivalente a 190.519.297 pessoas ${ }^{[18]}$. O número médio de pessoas por família é de 3,30, uma redução quanto à POF 20022003, que era de 3,62 pessoas ${ }^{[19]}$.

A base de dados BI-PROHORT deveria apresentar informações para sessenta e uma unidades de CEASA, que também constituiriam o Sistema de

11 Hospedado no site:

http://dw.prohort.conab.gov.br/pentaho/Prohort. 
Informações dos Mercados de Abastecimento do Brasil (SIMAB). Porém, em maio de 2010, a tabulação de dados junto a essa base trouxe informações para apenas vinte e seis centrais atacadistas, além de não se ter encontrado no site da Companhia Nacional de Abastecimento (CONAB) referência acerca da entrada em operação do SIMAB. Cabe destacar que o banco de dados - BI-PROHORT - é um dos mais relevantes ganhos conferido pelo PROHORT ao mercado atacadista de hortifruti [1]. Esse banco de dados não disponibiliza informações sobre a origem dos produtos comercializados nas centrais de abastecimento. Cunha [1] salienta a inexistência de dados acerca do setor atacadista de hortigranjeiros, de modo geral, no país.

Há aproximadamente trinta anos, a ABRAS divulga, por meio da revista SuperHiper ${ }^{12}$, o Ranking dos supermercados brasileiros, que busca fornecer um retrato do varejo de alimentos do país em termos de concentração, tamanho de lojas, índices de eficiência, faturamento, número de funcionários. Cabe à empresa ACNielsen tabular as respostas dadas aos questionários preenchidos pelos supermercadistas. No mais, para elaborar o Ranking, são coletadas informações de quinhentas empresas - por volta de $59 \%$ do setor cujo faturamento mínimo anual seja $\mathrm{R} \$ 100.000$ e o número de checkouts, maior do que dois. Isto é, para a ABRAS, padarias e correlatos são enquadrados como supermercados, o que facilita a construção de uma base de quinhentas empresas, podendo-se, assim, amenizar a concentração existente no varejo de alimentos [20]. Infelizmente, não foi possível ter acesso a dados referentes ao volume comercializado por outros equipamentos como: feiras livres, quitandas, sacolões, mercados municipais.

Trabalhou-se com informações o mais recente possíveis, ou seja, com o biênio 2008-2009.

\section{DIREITO HUMANO À ALIMENTAÇÃO: MARCO CONCEITUAL E LEGAL PARA POLÍTICA DE ABASTECIMENTO ALIMENTAR}

Em 2004, a Organização das Nações Unidas para Agricultura e Alimentação (FAO/ONU) elaborou o documento "Diretrizes Voluntárias: em apoio à realização progressiva do Direito à Alimentação

\footnotetext{
12 Os exemplares consultados foram: Ranking ABRAS 2010 - ano 36, n. 407, abril 2010 e Ranking ABRAS 1997 - ano 23, n. 260, abril 1997.
}

Adequada no contexto da Segurança Alimentar e Nutricional" [21], que busca orientar os Estados na efetivação do direito ao alimento no contexto da SAN. Para sua elaboração foram considerados documentos resultantes de acordos internacionais que atestam o direito de todas as pessoas a um nível de vida adequado de modo a lhes assegurar saúde, bem-estar, alimentação e moradia. Esses documentos são: Declaração Universal de Direitos Humanos; Pacto dos Direitos Econômicos, Sociais e Culturais; Carta das Nações Unidas. Gordillo \& Gómez [22] afirmam que as Diretrizes Voluntárias representam o reconhecimento de que a fome e a má nutrição seriam mais bem explicadas por fatores socioeconômicos.

Com base nesse documento [21] e em autores como Valente [13], Pinheiro [15] e Gordillo \& Gómez [22], infere-se que pertencem ao DHA, os seguintes elementos: (1) alimentação baseada em uma combinação de produtos nutritivos suficientes para atender as necessidades fisiológicas dos seres humanos em todas as etapas do ciclo vital; (2) a produção, distribuição e comercialização de alimentos ocorre de forma a permitir o acesso aos alimentos tanto a gerações presentes quanto futuras, ou seja, é sustentável; (3) os alimentos se adequam às condições sociais, econômicas, culturais, climáticas e ecológicas da sociedade; (4) os alimentos são inócuos e para isso adotam-se medidas de proteção sob meios públicos ou privados; (5) o reconhecimento de que há valores não intrinsecamente relacionados com a nutrição que acabam servindo para caracterizar os alimentos, ou seja, diferenças culturais são respeitadas; (6) sistemas de distribuição e comercialização funcionam adequadamente para garantir que a produção chegue ao consumidor e (7) os alimentos são acessíveis economicamente, isto é, sua aquisição não compromete a satisfação de outras necessidades básicas.

$\mathrm{Na}$ medida em que esses elementos são alcançados, a realização do DHA ocorre. São elementos relacionados tanto ao crucial fomento do acesso monetário, quanto à organização da cadeia produtiva em si. Em termos de arcabouço normativo, o Brasil teria dado passos importantes para sair do plano do discurso, o que pode ser destacado como uma exceção. Por outro lado, não foi determinada alocação de recursos orçamentários para se manter um sistema nacional de SAN com base na realização progressiva do DHA; não se estabeleceram medidas voltadas para assegurar a progressividade da tributação, o que constituiria uma medida relevante em termos de 
geração de recursos para financiar medidas mais incisivas para a realização desse direito [23]. Nessa perspectiva, Mcinerney-Lankford [24] ressalta que dificilmente os direitos humanos são tratados além do discurso político pelos governos, ou seja, não são articulados com políticas de desenvolvimento, instrumentos para sua realização.

De fato, o compromisso assumido pelo Estado brasileiro com a realização do DHA tem se consubstanciado em programas sociais que visam ao acesso à renda sob perspectiva de discriminação positiva. Dessa forma, o Estado protege aqueles grupos considerados vulneráveis por estarem em situações que os fragilizam para adquirir seus próprios alimentos [25]. Dentro das transformações da amplitude do papel do Estado, a partir de meados da década de 1980, Fonseca [14] afirma que a "[...] focalização foi concebida como meio para garantir o acesso a direitos universais", o que se pode entender como sendo um primeiro passo no enfrentamento de situações de carestia. Ou ainda, que em um quadro de latentes desigualdades sociais, caso do Brasil, não seria razoável se utilizar de instrumentos de política que tratassem todos de forma igual [26].

Em meio à incorporação do DHA como direito social, na década de 2000, o Ministério do Desenvolvimento Social e Combate à Fome (MDS) por intermédio da Secretaria de Segurança Alimentar e Nutricional (SESAN) trabalha com abastecimento sob a diretriz da construção de equipamentos públicos para alimentação e nutrição dos tipos: restaurantes populares, cozinhas comunitárias, bancos de alimentos [27], bem como na lógica das microintervenções. Essas são medidas voltadas para o incentivo da produção local, para promover alternativas de comercialização aos pequenos produtores, racionalização da comercialização atacadista e varejista [28]. Esse enfrentamento deveria constituir um primeiro passo para a reestruturação do sistema alimentar brasileiro.

No entanto, tratamento das alterações na forma como os equipamentos varejistas supermercados, feiras livres, quitandas, sacolões conduzem suas relações com produtores, consumidores e atacado não foi efetivamente introduzido em programas de política pública [29]. Transformações acarretadas pelos supermercados na comercialização de FLV podem ser apercebidas por meio da dimensão que esses equipamentos detêm junto à população urbana do país. Dados da ACNielsen, apresentados por Martins et al. [30], mostram que no período 1981/82, cerca de 90,2\% das frutas, em média, eram adquiridas pelos consumidores brasileiros em feiras livres contra apenas $5 \%$ adquiridos nos supermercados. Em 1998/99, tal disposição se inverteu, isto é, nas feiras livres $54 \%$ das frutas eram adquiridas e nos supermercados $33 \%$, o que teria representado aumento de 577,11\% na comercialização de frutas pelos supermercados. Em 2003, pesquisa da Latin Panel ${ }^{13}$ demonstrou que 46\% dos brasileiros entrevistados declararam não comprar FLV em supermercados, o que teria caído para 31\%, em 2007. Por outro lado, apenas $30 \%$ declararam exclusividade ao supermercado como local de compra desses alimentos. Atualmente, 39\% da população brasileira adquire esses alimentos tanto em supermercados como em outros equipamentos [31]. Portanto, os canais pelos quais a população pode adquirir tais alimentos têm se centrado em feiras e supermercados.

Em outro aspecto, a possibilidade de pagamento a prazo em supermercados não parece constituir preferência em relação a feiras livres, por exemplo. Como os dados da POF-IBGE de 2008-2009 mostram, frutas e hortaliças foram maciçamente adquiridas à vista, em 2008: $24 \mathrm{Kg}$ de hortaliças e 26 $\mathrm{Kg}$ de frutas, o equivalente em termos respectivos a $98 \%$ e $99 \%$, da forma monetária de aquisição nesse ano.

O consumo diário de frutas e hortaliças é requisito para uma alimentação adequada, uma vez que pressupõe uma ingestão da maior parte dos micronutrientes essenciais para nutrição, além do aumento do consumo desse alimento contribuir para substituir alimentos com altas concentrações de gorduras saturadas, açúcar e sal [32]. Junqueira \& Peetz [11] lembram que a má nutrição advém da falta de micronutrientes como vitamina A, ferro, antioxidantes, betacaroteno e iodo. Nesse sentido, relatório divulgado, em 2008, pela World Health Organization/Food and Agricultural Organization (WHO/FAO) traz a recomendação de consumo diário de pelo menos $400 \mathrm{~g}$ de FLV para prevenir doenças crônicas nãotransmissíveis (DCNT) - doenças cardiovasculares e diversos tipos de câncer. Frutas e hortaliças são também fontes de fibras, exercendo papel relevante no bom funcionamento intestinal e, por conseguinte, na eliminação de impurezas, bem como na redução da absorção do mau colesterol alimentar [11]. Em relação à recomendação da $\mathrm{WHO}$, o consumo desses alimentos

13 Informações divulgadas na revista Hortifruti Brasil CEPEA Esalq/USP, ano 9, n. 94, p. 4, set/2010. 
pela população brasileira ainda é modesto, tendo em vista restrições, principalmente, de origem socioeconômica [32].

É elementar que a geração de emprego e renda, bem como a promoção de menores níveis de desigualdades sociais, constituam aspectos diretamente relacionados com o acesso aos alimentos. A desigualdade da distribuição de renda, no Brasil, desde 2004 teria apresentado substancial redução, porém, em comparação com outros países, permaneceria alta [19]. A média da renda familiar per capita, com base em valores monetários da POF - 2002/2003 e 2008/2009, em R\$ referentes a janeiro de 2009 - teria crescido de 696,6 para 838,6 - um aumento de 20,4\%, tendo sido maior na área rural $(+36,2 \%)$ do que na urbana $(+19,1 \%)^{14}$, com base em Hoffmann [19]. Ainda de acordo com o autor, o índice de Gini se reduziu: em 2002-2003 foi 0,591 e, em 2008-2009 0,561, o que seria coerente com os dados da Pesquisa Nacional por Amostra de Domicílio (PNAD), haja vista apontarem para uma queda na desigualdade dos rendimentos - em 2002 o índice de Gini foi de 0,544 e, em 2008 foi de 0,544. Por outro lado, maior poder de compra não garante que a população consumirá alimentos mais nutritivos [11,33].

Gomes Júnior [33] afirma que uma política pública que tem a SAN por princípio se insere em um contexto de construção de condições para satisfazer as necessidades humanas básicas. A partir disso, tem-se a capacitação dos indivíduos, isto é, "várias combinações de vetores de funcionamentos que uma pessoa pode realizar, representando a liberdade da pessoa levar o tipo de vida que ela tem razão para levar". Tratar da questão do acesso aos alimentos significa a valorização fisiológica do homem [34] e a carência de nutrientes na dieta alimentar - como aqueles existentes em FLV constitui fator para reduzir a capacidade da população em se desenvolver como seres humanos plenos.

De fato, o consumo de hortifruti pela população brasileira não alcança a proporção recomendada pela Organização Mundial da Saúde. Com base nos dados POF: em 2008, a aquisição per capita anual de frutas foi de 76 gramas por dia e de hortaliças, 74 gramas diárias. Respectivamente, 17,8\% maior e 6,64\% menor do que em 2002. Tomando-se essa aquisição por estrato de rendimento mensal, sublinha-se que, em 2008, as famílias com rendimento de até dois salários, adquiriram, por dia, 42 gramas de

\footnotetext{
$14 \mathrm{O}$ autor cogita que esse aumento teria ocorrido em função da "urbanização" de algumas áreas rurais.
}

hortaliças e 38 gramas de frutas e despenderam 2,64\% de sua renda com esses produtos - equivalente a $\mathrm{R} \$$ 5,46. Familias com rendimento superior a quinze salários adquiriram 120 gramas de hortaliças e 161 gramas de frutas e despenderam em FLV 2,38\% de sua renda - em torno de $\mathrm{R} \$ 4,94$.

Alimentação é um dos itens com o qual a população brasileira mais gasta mensalmente: em 2008, representou $16 \%$ da despesa total - em torno de $\mathrm{R} \$$ 421,72 - e somente a população urbana teria despendido $R \$ 437,45$, o equivalente a $15,33 \%$ dos seus gastos mensais e $40,65 \%$ maior em relação a 2002 . As despesas das familias brasileiras consideradas na POF com hortifruti, em 2008, somaram $\mathrm{R} \$ 219,54$, o que representa 5,37\% das despesas com alimentação e $\mathrm{R} \$$ 51,37 a mais do que apresentado em 2002, mesmo que nesse ano as despesas monetárias mensais com hortifruti tenham representado $5,46 \%$ do total despendido com alimentação.

Em suma, como Belik \& Siliprandi [35] apontam, não somente é possível observar que as famílias brasileiras com menor rendimento gastam proporcionalmente mais com aquisição de alimentos, como também é possível observar hábitos alimentares menos saudáveis.

Esse quadro se distancia do conceito de SAN acordado na II Conferência Nacional sobre o tema, realizada na cidade de Olinda (PE), 2004:

\footnotetext{
Segurança alimentar e nutricional é a realização do direito de todos ao acesso regular e permanente a alimentos de qualidade, em quantidade suficiente, sem comprometer o acesso a outras necessidades essenciais, tendo como base, práticas alimentares promotoras de saúde, que respeitem a diversidade cultural e que sejam social, econômica e ambientalmente sustentáveis (MALUF, 2007, p. 144) [36].
}

A carência de determinados nutrientes leva ao que Josué de Castro [37] denominou fome oculta, que seria "forma típica da fome de fabricação humana". Várias razões, ao ver do autor, tornaram a fome oculta uma calamidade dos grupos humanos mais civilizados: "a primeira delas é a monotonia alimentar, imposta pela civilização, é o hábito do homem civilizado de nutrir-se à base de um número restrito de substâncias alimentares". O consumo de maior quantidade de 
alimentos deve se dar em consonância com maior valor nutricional.

Delgado \& Theodoro [38] lembram que, a Constituição Federal do Brasil de 1998 traz a igualdade como um princípio basilar, sendo o acesso aos bens públicos fundamental para garantir a justiça distributiva e a promoção da igualdade sob ação legal do Estado. Nesse sentido, políticas governamentais assumem relevante papel, mas não poderiam se isolar da atuação de outras importantes instituições econômicas e sociais [39]. Encarando-se que o DHA põe a alimentação como um bem comum - tendo em vista a sua inclusão na Constituição Federal como direito social - ao Estado caberia zelar pela eficiência e equidade em elos como: produção, distribuição, comercialização e consumo.

Apesar de fundamental, a alimentação ainda não é uma vontade geral. Como assinala Schumpeter [40]:

E a não ser que exista um centro, o bem comum em torno do qual, ao menos no longo prazo, todas as vontades individuais gravitem, não chegaremos aquele tipo particular de volonté générale. [...] Essa vontade definida teria de ser implementada pela capacidade de observar e interpretar corretamente os fatos diretamente acessíveis a todos e joeirar criticamente as informações sobre os fatos que não o são (1984, p. 316317).

Promover a realização progressiva do direito à alimentação adequada requer uma compreensão abrangente da forma como o alimento é adquirido; aspectos diretamente relacionados ao trânsito do alimento precisam ser analisados e considerados em uma política pública específica. Afinal, é obrigação do Estado respeitar, proteger e tornar efetivo esse direito humano [21]. Damboriarena [41] lembra que FLV são produzidos sob uso de elevados níveis de insumos e defensivos, condição que afeta sua inocuidade, bem como causa impactos sobre o meio ambiente. Os preços dos hortifrutis são sazonais e por isso os produtores são vulneráveis a mudanças de comportamento do mercado [16]. Na relação entre acessibilidade econômica e a importância da regulação pública do abastecimento alimentar, já não existe um sistema público nacional de informação - aos moldes do SINAC - que permita relativo controle sobre os preços de produtos de hortifruti. Esses são alguns elementos do abastecimento de hortifruti que demandam presença do setor público ou refletem sua ausência. Couto [12] afirma que, na linha de prioridade do enfrentamento da insegurança alimentar, a "regulação pública do abastecimento seria elemento de suma importância para a consecução do objetivo de universalizar o acesso aos alimentos".

Nessa perspectiva, a elaboração e implementação do Sistema Nacional de Centrais de Abastecimento se mantém como uma das iniciativas mais bem sucedidas para viabilizar uma política nacional de abastecimento [42]. Com a intenção de organizar o mercado de hortigranjeiros, as CEASAs se tornaram referência na formação de preços, aumentaram as informações sobre o mercado hortigranjeiro para produtores e comercializadores e intensificaram os serviços de classificação e padronização [42,43]. Entretanto, mesmo que uma das motivações para o SINAC tenha sido possibilitar a oferta no varejo de hortigranjeiros a preços compatíveis com o poder de compra dos trabalhadores, era reduzida sua capacidade de "propiciar segurança alimentar a grupos tão díspares" [44]. Ao passo que para o período recente, o compromisso do País em realizar progressivamente o DHA é capaz de conferir tratamento amplo a essa questão, isto é, a atuação das centrais de abastecimento pode ser reformulada não apenas para aumentar a competitividade da cadeia hortifruti, como, principalmente - tendo em vista o objetivo desse trabalho - para apoiar o acesso a esse alimento.

Nessa seção, em um primeiro momento, discorreu-se a respeito do DHA em um contexto de SAN enfatizando-se a importância do consumo de frutas e hortaliças como um requisito para sua realização. Nessa perspectiva, argumentou-se que uma política de SAN deve lançar fundamentos para a regulação pública do abastecimento alimentar. Em síntese, o objetivo da seção "DHA: marco conceitual e legal para a política de abastecimento alimentar" foi conceituar o direito ao alimento e mostrar que sua realização progressiva também requer medidas do setor público para o abastecimento de hortifruti. $\mathrm{Na}$ próxima, argumenta-se que a inexistência de mecanismos de regulação pública para o abastecimento desses alimentos constitui um limite à efetivação do direito humano ao alimento. Tendo em vista as limitações típicas desse tema, optou-se por centrar essa análise na padronização e certificação desses alimentos. 


\section{OS LIMITES PARA A REALIZAÇÃO DO DIREITO HUMANO À ALIMENTAÇÃO NO BRASIL SOB A PERSPECTIVA DO ABASTECIMENTO DE FRUTAS, LEGUMES E VERDURAS (FLV)}

A realização progressiva do DHA é transversal a uma série de temas. Nesse trabalho, busca-se trazer essa questão à luz da atividade abastecedora de FLV. O acesso ao alimento também requer canais de distribuição e comercialização claros em sua organização, bem como regulamentação das características desses produtos alimentícios. Afinal, suas propriedades organolépticas determinam impactos tanto sobre o seu preço, quanto sobre a saúde humana. Acredita-se, então, que o estabelecimento de padrões comerciais e de embalagens do hortifruti deveria ser de responsabilidade do setor público. No Brasil, existe legislação para determinar critérios de qualidade para esses produtos. Seriam eles: Decreto no 6.268/2007, cujo órgão responsável pela fiscalização é o Ministério da Agricultura, Pecuária e Abastecimento (MAPA) e dispõe sobre identidade; padrão oficial de classificação; critérios para qualidade. Sobre o estabelecimento de sanções no caso de não cumprimento dessas normas sobre classificação, existe a Lei no 9.972/2000, a qual torna obrigatória a classificação, em todo o território nacional, de produtos vegetais quando destinados diretamente à alimentação humana e dentre suas punições, estão, advertência, multa e suspensão da comercialização do produto.

Há ainda a Instrução Normativa no 009/2002, que se vale de uma extensa lista de órgãos públicos responsáveis pela fiscalização do seu cumprimento, quais sejam: MAPA, Ministério da Saúde, Agência Nacional de Vigilância Sanitária, Instituto Nacional de Metrologia, Normalização e Qualidade Industrial do Ministério do Desenvolvimento, Indústria e Comércio Exterior. Essa Instrução Normativa dispõe sobre a regulamentação do acondicionamento, do manuseio e da comercialização dos produtos hortícolas in natura em embalagens próprias para a comercialização de maneira a assegurar sua qualidade e inocuidade, bem como a verificação das informações a respeito da classificação dos produtos hortifruti. É com base nela que programas para modernização das embalagens - que consistem na substituição das "caixas K" por caixas higienizáveis ou de papelão - usadas no âmbito dos entrepostos, vêm se pautando.
A fiscalização do cumprimento dessa legislação por órgãos encarregados não é de todo rigorosa, o que limita sua influência sobre a atuação do setor privado. Gutierrez \& Resende ${ }^{[10]}$ ressaltam que foi a partir da exigência por qualidade de mercados importadores, como o europeu, que se observou maior rigor na fiscalização pelo poder público do cumprimento da referida legislação no caso das frutas destinadas à exportação. No mercado doméstico, há crescente exigência por maior qualidade de FLV [28], porém não se observa efetiva padronização das características desses alimentos. Redes do varejo supermercadista buscam tornar a seção de vendas de FLV o mais atrativa possível, investindo em melhorias na qualidade desses produtos. Para tal, utilizam-se de instrumentos como o contrato com produtores, centros de distribuição, padronização da embalagem e softwares específicos. Essa seria a chamada distribuição moderna e aquela a cargo das CEASAs, seria a distribuição tradicional. Porém, distribuição moderna e tradicional são simultâneas no abastecimento alimentar [45].

Nessa seção, em um primeiro momento, ambos os modelos serão caracterizados para, em seguida, apresentar-se os meandros dessa simultaneidade, principalmente, em termos de classificação e padronização e, então, argumentar-se-á que as centrais públicas de abastecimento podem centralizar funções de reguladoras do abastecimento.

Centrais de distribuição são encaradas pelas grandes redes de supermercado como estruturas primordiais para o abastecimento contínuo das gôndolas de suas lojas, bem como para garantir a qualidade de seus produtos. $\mathrm{Na}$ central de distribuição, os produtos que chegam já foram comprados pelo supermercado, quer dizer, na distribuição moderna o momento da transação entre comprador e fornecedor prescinde da presença física da mercadoria. Essas centrais têm permitido a mecanização da manipulação física de produtos perecíveis como o são os hortifruti, além de representarem um sistema técnico adaptado à manutenção de grandes volumes físicos que conduzem a uma redução substancial dos custos. Representam, assim, um modelo de distribuição homogêneo, como que um prolongamento natural das operações de produção com funcionamento agregado das atividades [7. O "comércio moderno" se torna interface entre a produção e os consumidores, o que enseja inovações organizacionais para coordenar as atividades comerciais em massa. Dessa maneira, o comércio evolui para uma 
nova lógica de rentabilidade e de economias de escala [46].

Em um entreposto atacadista - espaços físicos onde produtores e atacadistas se reúnem para intercâmbio de hortigranjeiros, ocorrem simultaneamente as três funções relacionadas à troca: a decisão de compra, a manipulação física do produto que já está presente no momento da compra - e o pagamento das mercadorias. Ofertantes e demandantes se encontram fisicamente e a transação é imediata [43]. Para as grandes empresas supermercadistas a inexistência de informatização nos entrepostos que pudesse controlar o fluxo desses produtos, o uso de embalagens inadequadas, a falta de rigor quanto à qualidade são razões para sua inaptidão quanto à modernização do varejo. Dessa maneira, o termo atrasado é associado a esse aparato tradicional de distribuição, cuja origem - investimentos e corpo técnico - se assenta na construção de uma política de abastecimento, o que é relativamente abandonado pelo setor público [46].

Quão mais concentrada a estrutura varejista, menor o papel dos atacadistas [47]. No Brasil, em 2002, o faturamento das cinco maiores redes representava 38\% do faturamento das quinhentas empresas tomadas por base para o cálculo do Ranking ABRAS. Em 2009, esse índice passou para 63\%. Ao passo, que o faturamento das cinquenta maiores empresas do setor supermercadista representavam, em 2002, 49\% e, em $2009,88,55 \%$ do faturamento de todas as empresas consideradas pelo Ranking ABRAS. Esse grau de concentração facilitaria uma relação de oligopsônio entre o varejo supermercadista e os produtores, bem como reduziria o poder de mercado dos atacadistas. Em 2009, o faturamento das quatrocentas e quarenta e nove empresas supermercadistas, a partir da quinquagésima primeira, representou $12,27 \%$ do total (quinhentas empresas).

As duas maiores redes de supermercado do país - Companhia Brasileira de Distribuição e Carrefour Comércio Industrial Ltda. - detêm, cada uma, em torno de $20 \%$ do faturamento do setor. Ambas recorrem aos entrepostos atacadistas em situações especiais, como: quebra de safra, para compra de algumas frutas importadas e para suprir lojas localizadas no Nordeste do país. Por isso se afirma que as duas maiores redes do país fazem uso, apenas contingencial, dos entrepostos atacadistas. O supermercado Covabra, com $0,3 \%$ do faturamento total, depende do entreposto atacadista localizado em Campinas para comercializar esse produto em suas lojas. Essa empresa, assim como a rede Oba Horti Fruti, usa seus boxes na CEASA Campinas como uma espécie de central de distribuição em que há câmeras frias, pessoal recebendo e controlando os produtos que chegam e, então, saem para suas lojas. Nos boxes é também observado o controle de qualidade desses alimentos. Essas empresas não estabelecem contratos com produtores, isto é, suas compras seguem operações de mercado livre, como afirmaram seus gerentes de compras.

Pequenos varejistas, feirantes, restaurantes, além dos mercados institucionais constituiriam, cada vez mais, os principais clientes das centrais de abastecimento [38]. Nesse sentido, os gerentes de compras responsáveis pela área de vendas de hortifruti de redes como Carrefour e Companhia Brasileira de Distribuição afirmaram que os entrepostos atacadistas carecem de logística e de infraestrutura para atender a demanda das lojas de grandes redes. Porém, se mantêm importantes para o abastecimento de municípios brasileiros e de equipamentos menores de varejo.

Nas sete plataformas logísticas da Companhia Brasileira de Distribuição, a média diária de movimentação de frutas, legumes e verduras seria de 2.000 toneladas e a plataforma localizada na cidade de São Paulo corresponderia a $60 \%$ desse volume. No Grupo Carrefour, $86 \%$ das frutas e hortaliças comercializadas passam pelas plataformas, sendo a sua dinâmica de funcionamento concentrada em dia específico da semana. Em ambas essas redes, os gerentes entrevistados afirmaram não acreditar que $\mathrm{O}$ modelo CEASA vá se esgotar, porém como ele não supre as necessidades de abastecimento contínuo das lojas de redes grandes, o perfil dos seus clientes varejistas se modificou.

Com base em dados do BI-PROHORT, no período de 1995 a 2009, a comercialização de hortifruti pelos entrepostos brasileiros atingiu a quantidade total de 87,10 milhões de toneladas, isto é, $\mathrm{R} \$ 88,89$ bilhões. Desses, 69 milhões de toneladas correspondem a frutas e hortaliças. São constatáveis dois movimentos importantes: na década de 1990 o volume comercializado de hortaliças e frutas nos entrepostos foi constante, o que se reverte a partir de 1999, quando começa breve trajetória de expansão, até 2003, da quantidade ofertada de frutas e hortaliças. O setor hortigranjeiro, no período 2004-2009, ofertou 
quantidade de produtos expressiva e maior do que a ofertada nos anos anteriores e a quantidade ofertada de frutas e hortaliças apresentou o mesmo movimento, porém em proporção consideravelmente menor.

A CEAGESP, em 2009, comercializou 3,1 bilhões de toneladas de hortigranjeiros, o equivalente a $\mathrm{R} \$$ 4,89 bilhões, enquanto que a CEASA Campinas comercializou 659 milhões de toneladas de hortigranjeiros com um faturamento de $\mathrm{R} \$ 956$ milhões. A CEAGESP comercializa por dia 10.000 toneladas de FLV, flores e pescados, acarretando um fluxo financeiro diário da ordem de $\mathrm{R} \$ 15$ milhões. Recebe produtos de 1.500 municípios distribuídos entre 25 unidades federativas, além de 18 países. Em 2009, as centrais públicas, de modo geral, movimentaram 4,4 milhões de toneladas de hortigranjeiros, o que representou vendas de $\mathrm{R} \$$ 6,34 bilhões - com base em dados do BI-PROHORT.

Como destacam diferentes autores [48-51] a globalização agroalimentar culmina no uso da qualidade como um dos instrumentos principais de comunicação entre o varejo e o consumidor, haja vista a demanda para assumir significativo papel no ordenamento de cadeias agroalimentares. O ferramental logístico usado pelos supermercados no varejo de hortifruti constituiria uma forma de atender às exigências dos seus clientes. A fixação de normas em torno da aparência de FLV representa uma facilitação e ganhos nas trocas comerciais, dada a relativa homogeneização acarretada [49]. No mercado brasileiro não há, então, uma "dependência bilateral" entre distribuição e fornecimento, por outro lado, há um exercício de poder de oligopsônio da parte do varejo, que pode ser notado pela crescente co-responsabilidade pelas vendas entre fornecedores e supermercados ${ }^{[52]}$.

\section{Distribuição moderna e tradicional: importância da regulação pública na determinação de critérios para comercialização de Frutas, Legumes e Verduras (FLV)}

Entende-se por regulação pública o estabelecimento de regras que visam moldar o comportamento dos atores do setor privado no sentido de observarem as condições necessárias para que exista SAN e assim proteger interesses públicos por meio da regulação do setor privado. Essas regras podem envolver mecanismos de padronização, classificação dos produtos e de sistematização de informações [53]. O autor conclui que a "auto-regulação" é simbólica e se dá de maneira a contentar o público e prevenir a intervenção governamental.

No Brasil, a CEAGESP conta com o Centro de Qualidade em Horticultura (CQH) no âmbito do qual ocorrem estudos que visam a classificação, rotulagem e embalagem e tudo o mais que se relacionar as boas práticas de FLV. Para esse centro, com base na entrevista realizada com a técnica responsável, a fiscalização e o controle de padrões estabelecidos requerem presença mais incisiva do setor público por meio de investimentos em laboratórios e em pessoal para fiscalizar produtores e varejistas quanto à qualidade desses produtos. A ruptura, nos anos 1980, do SINAC impediu que essa organização e fiscalização comuns do nível da qualidade de FLV se consolidassem no funcionamento dos entrepostos atacadistas. Assim, cada equipamento estabeleceu os seus próprios critérios de qualidade e padrões e de embalagens, ou seja, não há linguagem comum entre as unidades de CEASA [43].

Com base em entrevistas realizadas com os gerentes de compras de hortifruti das redes Companhia Brasileira de Distribuição, Grupo Carrefour, Oba Horti Fruti e Supermercados Covabra, constatou-se que o estabelecimento dos seus próprios critérios sobre a aparência desses alimentos se dá a partir da observação da preferência de seus clientes. Os gerentes afirmaram que essas redes contam com laboratórios destinados a exercer controle sobre os níveis de agrotóxico desses produtos. Possuem conhecimento do trabalho de classificação elaborado e divulgado pelo CEAGESP, mas não o seguem, porque "ninguém o seguiria", uma vez que não há fiscalização rigorosa e disseminada do cumprimento dessas especificações para FLV. Acreditam na importância de um sistema de padronização e classificação nacional de hortifruti organizado e fiscalizado pelo poder público para sua rentabilidade e para os consumidores e até mesmo para os agricultores, porém não crêem que isso acontecerá.

Sobre as embalagens, esses gerentes afirmaram que a exigência aos atacadistas do uso de caixas plásticas - ou simplesmente a substituição das "caixas K", que algumas unidades de CEASA vêm fazendo ${ }^{15}$, não teria impactos sobre seus negócios, pois contam

\footnotetext{
15 Seriam elas: Banco de Caixas na CEASA do Rio Grande do Sul, Central de Caixas na CEASA de Uberlândia, LogiClean na CEASA de Campinas e Central de Embalagens "Governador Miguel Arraes" na CEASA de Pernambuco. Programas esses baseados em iniciativa da CEAGESP ocorrida em 2000.
} 
com seu próprio modelo de caixas adequadas para acondicionamento desses produtos. Ao passo que os gestores das CEASA Campinas e CEAGESP ressaltaram que os programas destinados a substituir caixas de madeira por caixas plásticas higienizáveis ou por caixas de papelão somente avançariam no âmbito dos entrepostos, se os supermercados - considerandose todos os tamanhos - passassem a exigir dos seus fornecedores o uso das caixas permitidas pelas centrais. Sublinha-se que redes como Carrefour e Companhia Brasileira de Distribuição erigiram um sistema de distribuição próprio orientado por critérios supostamente estabelecidos com base nas preferências de sua demanda - à margem de regulamentações do Estado.

O diagnóstico dos mercados atacadistas realizado pela CONAB, em 2009, revelou a existência no Brasil de setenta e dois entrepostos distribuídos geograficamente como segue: Sudeste 50\%; no Sul, 16\%; no Nordeste, 27\%; no Centro-Oeste, $6 \%$ e na Região Norte, $1 \%$. As 36 centrais de abastecimento da Região Sudeste comercializaram, em 2009, mais de sete bilhões de toneladas de produtos - hortigranjeiros representaram $86 \%$, isto é, seis milhões de toneladas. Considerando-se a localização dos entrepostos pelas áreas urbanas, nota-se que 12 deles estão situados em capitais sub-regionais ou centros locais que abrigam $47,3 \%$ da população brasileira, enquanto que 11 entrepostos atacadistas estão em 12 metrópoles, as quais abarcam $33,7 \%$ da população do país. Em termos de volume comercializado somente de FLV, aqueles mercados atacadistas ligados a metrópoles comercializaram $66,8 \%$ do total, o que representaria consumo de 168 quilogramas por habitante das metrópoles.

A localização geográfica dos supermercados com base nos dados do Ranking ABRAS 2010 - pode ser desenhada como segue: $51,2 \%$ das lojas na Região Sudeste com 54,86\% do faturamento total; $25,8 \%$ na Região Sul com 19,78\% do total; 18,6\% das lojas nas Regiões Norte e Nordeste com faturamento equivalente a 19,62\% do total. A Região Centro-Oeste conta com apenas $4,5 \%$ das lojas, as quais representam $5,74 \%$ do faturamento total divulgado pela ABRAS. Destaca-se o Estado de São Paulo com 32,1\% das lojas; Rio Grande do Sul, 14,5\%; Rio de Janeiro, 7,7\%; Minas Gerais, com 9,9\% e Bahia, com 9,2\% das lojas do setor apresentado no Ranking ABRAS 2010. Nesse mesmo ano, Amazonas, Maranhão, Amapá, Acre, Tocantins, Rondônia e Roraima juntos representaram 1,2\% do número de lojas. Há uma parte da população brasileira que não é abrangida pelos supermercados e, por conseguinte, pela seção de vendas de FLV destes. Os supermercados têm por objetivo atender a população financeiramente capaz de comprar seus produtos, logo, áreas em que não há potencial de consumo não interessam em termos de instalação de lojas. Outro aspecto importante é a dificuldade logística em abastecer com frutas e hortaliças lojas das Regiões Nordeste, sobretudo Norte, a partir de um centro de distribuição localizado em São Paulo, como afirmaram, em entrevista, os gerentes de compra das duas maiores redes do país aqui consideradas.

Os gerentes de compras entrevistados afirmaram que os produtos com maior qualidade e melhor aparência são destinados às lojas localizadas nos bairros mais nobres e/ou às bandeiras cujos clientes apresentam maior poder aquisitivo. Seria a segmentação de mercado. Enquanto que a variedade de produtos FLV nas lojas em bairros periféricos seria menor em relação à de lojas para consumidores com maior poder de compra. Autores como Campeão et al. [54] observaram o mesmo para a cidade de Campo Grande (MS) e Lima \& Godinho [55] o destacam para Goiânia (GO). Os gerentes do Carrefour e CBD afirmaram, ainda, que produtos próprios para o consumo, porém com aspecto menos apresentável costumam ser colocados à venda em lojas dessas empresas cujos clientes teriam menor poder de compra e/ou destinadas a promoções que ocorrem uma vez por semana, geralmente. Dessa forma, segundo eles, estariam contribuindo para garantir a SAN no país. Ao passo que os gerentes de compra de Oba Horti Fruti e Supermercados Covabra afirmaram que sua prioridade é atender clientes atentos à qualidade do produto e não tanto ao preço.

O sócio da empresa atacadista Benassi Distribuidores ressaltou, durante a entrevista, outros problemas de caráter empresarial das centrais de distribuição: apesar das redes estabelecerem contrato com o produtor, não há segurança quanto à entrega do produto; os funcionários que trabalham na central não são especializados e/ou bem instruídos; para o centro de distribuição funcionar bem, várias regras são estabelecidas o que acabaria gerando mais custos. A CBD, por exemplo, entregou o suprimento de suas gôndolas por FLV de todas as lojas da bandeira Pão de Açúcar para a empresa atacadista Benassi. Na perspectiva do abastecimento se deve considerar que o raio de atuação das plataformas logísticas se restringe às 
Regiões Sul, Sudeste e, em pouca medida, CentroOeste e Nordeste, de forma que o abastecimento de municípios e Estados distantes desse raio, são eminentemente abastecidos por centrais de abastecimento com destaque para o papel da CEAGESP. Como declararam os gerentes de compras do Carrefour e da CBD.

$\mathrm{Na}$ perspectiva do DHA, todos devem ter acesso a alimentos de qualidade [20], a qual, nesse estudo, está se considerando pelo aspecto nutricional (FLV) e de segurança do alimento. Dessa maneira, nem a oferta, nem a qualidade desses alimentos devem ser tratados em patamar superior às condições de acesso pela população.

\section{Reformulação das Centrais de Abastecimento (CEASAs): um passo importante para a realização progressiva do Direito Humano à Alimentação (DHA) no Brasil}

Acredita-se que o abastecimento das grandes cidades do país, organizado por CEASAs e sob a regulamentação de um órgão público federal representaria aproveitá-las em uma função para a qual foram de fato criadas. Coordenar e sistematizar informações de mercado constituem uma forma de regulação. Assim como organizar laboratórios para proceder à classificação e padronização de hortifruti; oferecer assistência técnica ao produtor de modo a induzir à rastreabilidade, permitindo a certificação. Essas são tarefas originalmente concebidas para as centrais de abastecimento ${ }^{[1,8]}$, que não foram de todo perdidas desde o fim do SINAC. Mantêm-se de acordo com os interesses de cada CEASA [i].

Cabe destacar iniciativas de teor modernizante adotadas, considerando-se apenas a CEASA Campinas e a CEAGESP, na década de 2000 (Quadro). Elas refletem a percepção de que a produção agroalimentar se modernizou de maneira que a atividade atacadista necessita de reformulações/adequações. Sem pertencer a um projeto maior, as CEASAs, para se renovarem, adotam medidas específicas e apartadas, o que pouco ou nada contribui para a realização progressiva do DHA. Ao mesmo tempo em que esses programas em curso (Quadro) indicam que as CEASAs são importantes - e podem ser ainda mais - para que se concretizem os elementos da realização do direito ao alimento. Principalmente quanto à inocuidade dos alimentos; eficiência dos sistemas de distribuição e comercialização; acessibilidade econômica e promoção de alimentação adequada.

O SINAC procurou concretizar o papel regulador do Estado por meio de um arranjo institucional e, por conseguinte, apoiar/fomentar relações mercantis neste setor ${ }^{[56}$. O SINAC, a partir de uma sistematização de informações de mercado; da reunião de produtores e atacadistas no mesmo espaço; do estabelecimento de critérios para padronizar hortigranjeiros; da adoção de medidas para desenvolver o varejo, deveria constituir referência para as trocas no mercado de FLV. É, sobretudo, na isonomia na geração de informações que está seu caráter estratégico e de bem público ${ }^{[1]}$.

A necessidade de revitalização das centrais de abastecimento no sentido de uma ampla coordenação nacional tem tão ou mais imprescindibilidade tendo-se em conta que:

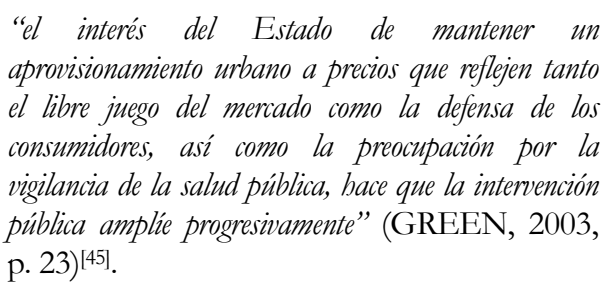

Ademais, como foi expresso no documento da FAO de 2008, Food for the Cities, a SAN exerce influência - e também é influenciada - sobre diferentes aspectos da economia urbana.

Do ponto de vista operacional centros de distribuição e centrais de abastecimento possuem as mesmas características. No âmbito dos entrepostos, os problemas relacionados à gestão, a falta de recursos financeiros, dentre outros, comprometem a percepção do papel das centrais. Não somente com base nas afirmações obtidas por meio da aplicação do método desse estudo - a entrevista semi-estruturada - mas também com base em Cunha [1], Green [45], Viteri [48] e González [57], afirma-se que não se trata de substituir os entrepostos pelas centrais de distribuição. Ambas constituem elementos de um todo complexo.

É superficial afirmar que os supermercados dêem conta da garantia de produtos com real qualidade - inocuidade, principalmente - à toda a população, de modo a se desmerecer uma regulamentação pública. Green \& Schaller ${ }^{[58]}$ destacam que é a logística a grande 


\begin{tabular}{|c|c|c|}
\hline $\begin{array}{c}\text { Centrais de } \\
\text { Abastecimento } \\
\text { (CEASA) }\end{array}$ & & Programas \\
\hline \multirow{5}{*}{$\begin{array}{l}\text { Companhia de } \\
\text { Entrepostos e } \\
\text { Armazéns } \\
\text { Gerais de São } \\
\text { Paulo } \\
\text { (CEAGESP) }\end{array}$} & Índice CEAGESP & Apoia a formação de preços em outros entrepostos atacadistas. \\
\hline & HortiEscolha & $\begin{array}{l}\text { O Centro de Qualidade em Horticultura (CQH/CEAGESP) } \\
\text { elabora fichas de alguns produtos para orientar as compras de } \\
\text { Frutas, Legumes e Verduras (FLV) para Serviços de } \\
\text { Alimentação - responsáveis pelo preparo de refeições fora do } \\
\text { lar. Isto é, elabora-se uma classificação do produto que o } \\
\text { caracterize da melhor maneira possível e uma base para a } \\
\text { negociação do preço. }\end{array}$ \\
\hline & Padronização da embalagem & $\begin{array}{l}\text { A modernização das embalagens usadas no entreposto ocorre } \\
\text { por adesão voluntária dos permissionários. }\end{array}$ \\
\hline & Apoio ao Produtor & $\begin{array}{l}\text { O CQH elabora e fornece informações técnicas sobre } \\
\text { classificação, rotulagem e embalagens de FLV. Os pequenos } \\
\text { produtores contam com o Barração CEAGESP do Produtor } \\
\text { cujo objetivo é apoiar grupos de produtores na classificação e } \\
\text { venda de seus produtos. }\end{array}$ \\
\hline & Tabela de período de safra & $\begin{array}{l}\text { Procura dirimir as oscilações de preços de hortifruti, } \\
\text { informando os meses de safra. }\end{array}$ \\
\hline \multirow{5}{*}{$\begin{array}{l}\text { CEASA } \\
\text { Campinas }\end{array}$} & Alimentação e Saúde & São colocadas informações no site da Central. \\
\hline & Padronização & $\begin{array}{l}\text { Procura seguir as orientações do Ministério da Agricultura, } \\
\text { Pecuária e Abastecimento (MAPA) para classificação e } \\
\text { padronização de hortaliças e frutas. Não há fiscalização do seu } \\
\text { cumprimento. }\end{array}$ \\
\hline & Banco de Caixas & $\begin{array}{l}\text { Implantado em 2010. Operacionalizado por uma empresa } \\
\text { privada. }\end{array}$ \\
\hline & Produtos de Época & $\begin{array}{l}\text { Procura dirimir as oscilações de preços dos produtos FLV, } \\
\text { informando os meses de safra. }\end{array}$ \\
\hline & Dados nutricionais de FLV & Ficha que especifica valores nutricionais desses alimentos. \\
\hline
\end{tabular}

Fonte: Elaboração própria a partir de informações disponibilizadas nos seus sites.

Quadro. Central de Abastecimento - CEASA Campinas e Companhia de Entrepostos e Armazéns Gerais de São Paulo - CEAGESP: programas voltados a induzir melhorias na atividade atacadista. 
responsável pela transformação do papel do atacado na comercialização de FLV ou pelo agigantamento do varejo. Enquanto que os entrepostos atacadistas contam com um aparato logístico incipiente e obsoleto, uma vez que se mantêm sendo públicos e os investimentos estatais em infraestrutura decaíram desde meados dos anos $1980[8]$.

Green [45], usando o mercado de Rungis na França e Mercasa, na Espanha, aponta que a renovação das centrais atacadistas passa pela incorporação de novos serviços, incluindo sua transformação em plataformas logísticas. Dessa maneira seria possível "añadir valor a los productos mediante diferentes servicios: recepción y control de mercaderías, de almacenamiento climatizado, acondicionamiento, maduración, empaquetado, preparación de lotes y distribuición de los productos" [44]. $\quad$ No Brasil, já se observa a emergência desse tipo de relação entre os entrepostos atacadistas e redes varejistas. Lima \& Godinho [55] mostram que a rede Bretas de supermercados - cuja sede está em Goiânia (GO) faria de seus boxes na CEASA (Goiás) uma espécie de central própria de distribuição. Para os gerentes de compra da Oba Horti Fruti e Covabra Supermercados, as centrais de abastecimento são imprescindíveis e os problemas que enfrentam não afetariam as transações comerciais dessas unidades varejistas.

Nessa perspectiva, mercado e Estado não são entes independentes um do outro no abastecimento. São complementares. Um exemplo é o trabalho que a CEASA Minas vem fazendo junto aos produtores de abacaxi. Os técnicos dessa CEASA notaram que os abacaxis oriundos de regiões distantes, apresentavam menores taxas de açúcar. Os técnicos sugeriram então, o uso de embalagens de papelão, tendo em vista atributos como proteção, eficácia no manuseio e transporte, economia no uso do capim/palha, limpeza nos locais de descarregamento. Os ganhos se deram como segue: o abacaxi transportado a granel de Tocantis (TO) a Contagem (MG), sofria perda de $41 \%$ e com caixa de papelão, esse volume se reduziu para $1 \%[59]$

O PROHORT concebe intenções de renovação da atividade atacadista em nível nacional no sentido proposto no Quadro. Entretanto, seus avanços se resumiram a estudos técnicos, implementação da base de dados BI-PROHORT - que para a técnica do CQH/CEAGESP, estaria aquém do potencial de informações das CEASAs - e resgate de documentos elaborados durante o SINAC. Esses avanços marginais podem ser explicados pela falta de recursos financeiros para executá-lo em toda sua complexidade. Cunha [1] esclarece que o PROHORT é um programa de diretrizes, desprovido de orçamento próprio e sem contar com linhas de financiamento para estudos ou investimentos; é definido como uma associação voluntária de ajuda mútua que se desenvolve sob coordenação de um agente público. Está vinculado à CONAB, sendo suas características e pretensões institucionais diferentes daquelas do SINAC.

Pode-se encarar esse programa de modernização como um projeto em fase de estruturação ou como um projeto que terá êxito, se obtiver financiamento ${ }^{16}$, apoio político e engajamento dos atacadistas. De todo o modo, representa uma iniciativa relevante para aprofundar as operações das centrais de abastecimento em direção ao moderno. $\mathrm{O}$ moderno nesse caso se define por uma dinâmica operacional eficiente: logística, a padronização de embalagens, controle rígido de qualidade expresso na certificação dos produtos são seus elementos principais. Os permissionários que atuam nos entrepostos precisam ser convencidos de que essa mudança vale a pena, de tal maneira que a atuação regulatória teoricamente intrínseca às CEASAs é o fator imprescindível. O PROHORT também pode ser encarado como uma iniciativa entre setor público e a Associação Brasileira de Centrais de Abastecimento (ABRACEN) para modernizar o mercado hortigranjeiro sem desmantelar ou privatizar as centrais de abastecimento, visto que suas proposições se concentram no funcionamento do entreposto atacadista.

\section{CONSIDERAÇÕES FINAIS}

Ao reunirem entes da cadeia de frutas, legumes e verduras em um único espaço físico, as centrais de abastecimento, se coordenadas, permitem organização de mercado por meio da sistematização e centralização das informações sobre preços, além do estabelecimento de padrões de qualidade. No Brasil esse modelo de funcionamento se degenerou com a retirada do poder público de seu planejamento e coordenação, nos anos 1980. Ademais, as centrais de abastecimento tiveram sua função exaurida em meio a processos de globalização e internacionalização. Sob esses processos, sobressaíram-se os investimentos realizados por supermercados em logística, conformando as centrais

\footnotetext{
16 Supermercadistas contam com espaço para obter financiamento junto ao Banco Nacional do Desenvolvimento Econômico e Social (BNDES), ao passo que não existem linhas especiais para Centrais de Abastecimento (Revista Super Hiper).
} 
próprias de distribuição. A essas estruturas atribui-se o conceito de moderno, haja vista engendrar especialização de funções - quais sejam: financeira, manipulação física, informacional - sob o uso das Tecnologias de Informação e Comunicação e da logística. Os centros de distribuição permitem aos supermercados promover maior controle sobre a produção e distribuição de hortifruti, bem como influenciar a aquisição dos mesmos pelos consumidores.

Relativamente às centrais privadas de distribuição, as CEASAs, estão no limite do arcaico, mas não sem possibilidade de modernização. Desde meados dos anos 2000, é crescente o número de unidades brasileiras de CEASA que buscam meios para sua modernização. Tal movimento se dá, principalmente, pela adoção de programas voltados para a padronização de embalagens, embora seus resultados não tenham sido sistematizados pelas centrais a ponto de se poder afirmar o nível de êxito que têm obtido. Ambas as centrais tratadas nesse trabalho - CEASA Campinas e CEAGESP destacam-se na elaboração de programas de cunho renovador da atividade atacadista, como a substituição de caixas de papelão por caixas higienizáveis e até mesmo pela classificação de frutas e hortaliças.

O caminho para a realização progressiva do DHA inicia pelo comprometimento do Estado em assegurar alimentos em quantidade e em qualidade adequados para toda a sua população. O governo brasileiro tem expresso vontade política nesse sentido por meio da promulgação da LOSAN e da incorporação da PEC 47/03 aos direitos sociais da Constituição Federal. Comer, então, é um direito humano e o Estado é o agente principal para garantir o seu cumprimento. Atrelar o acesso aos alimentos a um direito humano engendra uma nova perspectiva, ou seja, assegurar que todos os cidadãos de um país se alimentem de maneira quantitativa e qualitativamente adequada passa a constituir um dever moral. É com base nesse compromisso assumido que se argumentou sobre a importância da presença do setor público no abastecimento de hortifruti.

As limitações relacionadas à presença do setor público brasileiro no abastecimento alimentar se referem, principalmente, à inexistência de um aparato institucional organizado e implementado pela união. Regular o abastecimento de FLV via centrais de abastecimento representaria, principalmente, renovar estruturas que foram originalmente inseridas como instrumento fundamental para comercialização desses alimentos. Representaria, ainda, aproveitar e melhorar o espaço físico dos entrepostos atacadistas, bem como o conhecimento técnico a respeito do setor construído desde que foram criados.

Além da oferta, características organolépticas do hortifruti afetam seu preço. São alimentos indispensáveis para uma alimentação adequada e, se não consumidos, podem desencadear problemas de saúde pública. Nesse caso, compromete-se o desenvolvimento humano; o desenvolvimento de capacidades. Dentro do conceito de SAN que foi usado, uma dieta pobre ou insuficiente nesses alimentos torna-se uma questão a ser tratada no âmbito de uma política de SAN.

A conformação entre o setor público e o privado brasileiros no "fazer chegar esses alimentos até a população urbana" é dúbia e com pouca delimitação. As ações dentro das CEASAs são cada vez mais fragmentadas, ou seja, específicas para determinados problemas sem uma preocupação com o modelo sistêmico que deveria articular interesses e necessidades das partes envolvidas no abastecimento. No limite, não é possível ser categórico a respeito de qual modelo é mais eficiente - se o moderno ou o tradicional. Outrossim, pode-se dizer que, no Brasil, ambos convivem e que ambos apresentam falhas do ponto de vista do abastecimento alimentar. Dentro do objetivo em realizar progressivamente o DHA, as centrais de abastecimento têm muito a contribuir, como se expôs na seção sobre os limites para a realização do DHA no Brasil.

\section{REFERÊNCIAS}

[1] Cunha ARAA. O sistema atacadista brasileiro: origens e destinos [tese]. Campinas: Universidade Estadual de Campinas; 2010.

[2] Linhares MYL, Silva FCT. História da política do abastecimento. Brasília: Binagre; 1979.

[3] Campino CC. A economia da alimentação e nutrição (noções básicas). Série Ensaios Econômicos - USP, v. 42, São Paulo; 1985.

[4] Maluf RS. Um "Mal Necessário?" Comercialização Agrícola e Desenvolvimento Capitalista no Brasil [tese]. Campinas: Universidade Estadual de Campinas; 1988. 
[5] Rozas P. América Latina: problemas y desafíos del financiamiento de la infraestructura. Cepal Rev. 2010;101:5983.

[6] Landi M. A evolução do Programa Nacional de Desestatização (PND): seus principais resultados e desdobramentos na infraestrutura. In: Marques AR, Ferreira MRJ. O Brasil sob a nova ordem: a economia brasileira contemporânea - uma análise dos governos Collor e Lula. São Paulo: Editora Saraiva;2010. p. 119-66.

[7] Reardon T, Berdegué JA. The rapid rise of supermarkets in Latin America: Development. Policy Rev. 2002;20(4):37188.

[8] Mourão IRA, Magalhães JSB. Breve História do Mercado atacadista de hortigranjeiros no Brasil. Revista de Administração Municipal do Intituto Brasileiro de Administração Municipal (IBAM), n. 9; 2009.

[9] Mourão IRA. Quanto custa para implantar um novo sistema nacional de CEASAs? Revista Abastecer, Belo Horizonte, n.1, p.70, abril/2010.

[10] Gutierrez ASD, Resende JV. Classificação de frutas: governo corre contra o tempo para atender europeus. Informações Econômicas. 2002;32(11):56-60.

[11] Junqueira AH, Peetz MS. Fome Oculta. Agroanalysis. 2001;21(8):8-12.

[12] Couto EP. O abastecimento alimentar no Brasil de 1930 à atualidade. Anais: VI Encontro Nacional de Economia Política, 12 de junho a 15 de junho de 2001. São Paulo-SP.

[13] Valente FLS. Fome Zero, Política Nacional de Segurança Alimentar e Nutricional e a promoção do Direito Humano à Alimentação Adequada. In: Relatório dos Direitos Humanos no Brasil 2005. São Paulo; 2005. Rede Social de justiça e direitos humanos: São Paulo-SP.

[14] Fonseca A. Los sistemas de protección social en América Latina: focalización us universalidad. Iniciativa América Latina Y Caribe Sin Hambre/FAO. Santiago do Chile, Working Paper n. 4, 2008. 17p.

[15] Pinheiro ARO. Reflexões sobre o processo histórico/político de construção da Lei Orgânica de Segurança Alimentar e Nutricional. Seg Alim Nutr. 2008;15(2):1-15.

[16] Oliveira ALR, Rocha P. O papel da logística na cadeia de produção dos hortifrutis. Instituto de Economia Agrícola APTA - Secretaria de Agricultura e Abastecimento, 2005. 4p. [acesso em 20 maio 2011]. Disponível em:
http://www.iea.sp.gov.br/out/Ler'Texto.php?codTexto=216 $\underline{0}$

[17] Friedman H. The political economy of food: the rise and fall of the postwar international food order. Am J Sociol. 1982;88(Suppl):248-86.

[18] Instituto Brasileiro de Geografia e Estatística. Pesquisa de Orçamentos Familiares 2008-2009: notas técnicas. 28p. Rio de Janeiro: IBGE; 2010.

[19] Hoffmann R. Progressividade e regressividade de parcelas de rendimento familiar no Brasil em 2008-2009. Mimeo. 13p. 2010.

[20] Departamento Intersindical de Estatística e Estudos Socioeconômicos. O Ranking dos supermercados: internacionalização e concentração. 2003. 8 p. [acesso em 14 maio 2011]. Disponível em: http://www.comerciarios.org.br/dieese/pesquisas/supermer cados-16-09-03.pdf

[21] Food and Agriculture Organization. Diretrizes voluntárias: em apoio à realização progressiva do direito à alimentação adequada no contexto da segurança alimentar nacional. Roma, 2004. 34p.

[22] Gordillo G, Gómez H. Derechos humanos y desigualdad: el contexto de la lucha contra el hambre. In: Gordillo G, Gómez H. (Org.) Derecho a la alimentación en el Brasil de Lula. Brasilia: UnB/CEAGRI/NEAGRI, 2004.

[23] Pol JLV, Monterroso LE. Comer es un derecho en América Latina: avances legales y políticos a favor del derecho a la alimentación. Iniciativa América Latina Y Caribe Sin Hambre/FAO. Santiago do Chile Working Papers, n. 3, 03/2008. 28p.

[24] Mcinerney-Lankford S. Human Rights and development: a comment on challenges and opportunities from a legal perspective. J Hum Rights Practice. 2009;1(1):51-82.

[25] Habib B. Droits de l'homme et alimentation. In: BOURRINET, J.; FLORY, M. Bourrrinet J, Flory M. L'ordre alimentaire mondial. Paris: Economica; 1982.

[26] Belik W. Políticas públicas, pobreza rural e segurança alimentar. Carta Social e do Trabalho, Cesit-Unicamp. 2006;4:42-55.

[27] Ministério do Desenvolvimento Social. Relatório de avaliação do plano plurianual 2008-2011. Brasília-DF: Subsecretaria de Planejamento e Administração, 2009. 
[28] Insituto de Cidadania. Projeto Fome Zero: uma proposta de política de Segurança Alimentar para o Brasil. 3a versão. São Paulo; 2001.

[29] Cunha ARAA. Dimensões estratégicas e dilemas das Centrais de Abastecimento no Brasil. Revista de Política Agrícola. 2006;4:37-46.

[30] Martins VA, Margarido MA, Bueno CRF. Alteração no perfil de compra de frutas, legumes e verduras nos supermercados e feiras livres na cidade de São Paulo. Informações Econômicas. 2007;37(2):30-37.

[31] Hortifruti Brasil. É viável ser fornecedor desse cliente? CEPEA - Esalq/USP. 2010;9(94):4.

[32] Gomes FR. Rastreabilidade: problemas referentes à rastreabilidade de frutas e hortaliças e impactos no trabalho das Visas na identificação e responsabilidade do setor primário. Apresentação Agência Nacional de Vigilância Sanitária (ANVISA). Búzios-RJ, 23 de novembro de 2007. 46p.

[33] GOMES JÚNIOR, Newton Narciso. Segurança Alimentar e Nutricional como princípio orientador de políticas públicas no marco das necessidades humanas básicas [tese]. Brasília: Universidade de Brasília; 2007.

[34] Marin SR. Karl Popper e Amartya Sen: temas para pensar em intervenção social e desenvolvimento humano [tese]. Curitiba: Universidade Federal do Paraná; 2005.

[35] Belik W, Siliprandi E. Hábitos alimentares, segurança e soberania alimentar. In: Vilarta R. et al. Qualidade de vida: evolução dos conceitos e práticas no século XXI. Campinas: Ipes; 2010. p. 187-95.

[36] Maluf RS. Segurança Alimentar e Nutricional com valorização da cultura alimentar. In: Miranda DS, Cornelli G. Cultura e Alimentação: saberes alimentares e sabores culturais. São Paulo: Sesc; 2007. p. 143-50.

[37] Castro J. Geopolítica da fome: ensaio sobre os problemas de alimentação e de população. São Paulo: Brasiliense, 1968.

[38] Delgado GC, Theodoro M. Desenvolvimento e política social. In: Jaccoud L. (Org.). Questão social e políticas sociais no Brasil contemporâneo. Brasília: IPEA; 2005. p. 408-35.

[39] Sen A. Desenvolvimento como liberdade. São Paulo: Companhia das Letras; 2000.

[40] Schumpeter JA. Capitalismo, socialismo e democracia. Rio de Janeiro: Zahar; 1984.
[41] Damboriarena E. Certificação e rotulagem na cadeia de hortigranjeiros no Estado do Rio Grande do Sul: um estudo de caso - Ceasa/RS [dissertação]. Porto Alegre: Universidade Federal do Rio Grande do Sul; 2001.

[42] Carvalho JL. CEASAs: novas estratégias para velhas funções. Revista HortiFruti Brasil. 2006;5(52):6-12.

[43] Favero LA. Novas formas de coordenação das atividades de abastecimento nos mercados atacadistas de frutas e hortaliças na América Latina. XXXIX Congresso da Sober. Recife: SOBER, 2005, 16p.

[44] Vilela MR. O abastecimento e o setor público agrícola. Sinac. 1978. 9p. [acesso em 20 maio 2011]. Disponível em: http://www.ceasa.gov.br/dados/publicacao/pub29.pdf

[45] Green R. Mercados Mayoristas el inicio de una nueva era? Distribuición y Consumo. 2003;13(72):23-37.

[46] Nascimento WG. As Centrais Públicas de Abastecimento no Contexto da Globalização dos Alimentos. Entre as Mudanças na Forma de Atuação do Estado e o Fortalecimento dos Grandes Distribuidores: O Caso do CEASA-PE [dissertação]. Pernambuco: Universidade Federal de Pernambuco; 2008.

[47] Cadilhon J, Fearne AP, Hughes DR, Moustier P. Wholesale markets and food distribution in Europe: new strategies for old functions. Discussion Paper n.2, Imperial College London: Centre for Food Chain Research; 2003.

[48] Viteri ML. Buenos Aires fruit and vegetable wholesale market: analysis proposal Villa Giardino. Cordoba: XXXVII Annual meeting of the AAEA; 2006.

[49] Busch L. The moral economy of grades and standards. J Rural Stud. 2000;16:273-83.

[50] Balsevich F. Supermarkets and produce quality and safety standards in Latin America. Am J Agric Econ. 2003;85(5):1147-54.

[51] Cavalcanti JSB. New challenges for the players in global agriculture and food. International Journal of Sociology of Agriculture and Food. 2004;12(1):29-36.

[52] Belik W. Mecanismos de coordenação e distribuição de alimentos no Brasil. In: Belik W, Maulf RS. (Org.). Abastecimento e Segurança Alimentar: os limites da liberalização. Campinas: Instituto de Economia Unicamp; 2000. p.131-59. 
[53] Havinga T. Private regulation of Food Safety by supermarkets. Law Policy. 2006;48(4):515-33.

[54] Campeão P, Oliveira LDS, Watanabe EAM, Ramos GGL. Logística interna de frutas, legumes e verduras (FLV) em supermercados: um estudo multicasos em Campo Grande. XLVI Congresso da Sociedade Brasileira de Economia, Administração e Sociologia Rural: Rio BrancoAC, 20 a 23 de julho de 2008. 20p.

[55] Lima AF, Godinho RG. Rastreamento da cadeia hortifrutigranjeira a partir da rede de Supermercados Bretas em Goiânia. Boletim Goiano de Geografia. 2008;28:189-96.

[56] Mazon MS.Padrões de qualidade e segurança alimentares no terreno institucional brasileiro. Dados. 2009;52(4):100345 .

[57] González MR. La eficiencia del comercio mayorista y su aportación a la seguridad alimentaria: la experiencia española de la Red Mercasa. Distribución y Consumo. 2003;72(13):917.

[58] Green R, Schaller B. Rationalisaton commerciale et mise em marche de produits alimentaires. Paris: INRA, Février; 1996.

[59] Conegundes A, Andrade V. Para ficar no ponto real da doçura. Revista Abastecer Brasil. 2010;2:22-25. 